GmbH Roche Pharma Rheumazentrum Rhein-Ruhr Sanofi-Genzyme Deutschland $\mathrm{GmbH}$ Swedish Orphan Biovitrum GmbH UCB Pharma $\mathrm{GmbH}$, Speakers bureau: AMGEN GmbH AbbVie Deutschland GmbH \& Co. KG Biogen GmbHBristol-Myers Squibb Celgene $\mathrm{GmbH}$ Chugai Pharma arketing Ltd. / Chugai Europe GmbHHexal Pharma Janssen-CilagGmbH Johnson \& Johnson Deutschland GmbHLilly Deutschland GmbH / Lilly Europe / Lilly Global Novartis Pharma GmbH Pfizer Deutschland GmbH Roche Pharma Rheumazentrum Rhein-Ruhr Sanofi-Genzyme Deutschland GmbH Swedish Orphan Biovitrum GmbH UCB Pharma GmbH, Rainer Freynhagen Consultant of: AOP Orphan Pharma, Grünenthal, Lilly, Merck, Mitsubishi Tanabe Pharma, Pfizer, Scilex Pharmaceutics, Speakers bureau: AOP Orphan Pharma, Grünenthal, Lilly, Merck, Mitsubishi Tanabe Pharma, Pfizer, Scilex Pharmaceutics, Thomas Tölle Consultant of: AOP Orphan, Almiral Hermal, Bionest Partners, Benkitt Renkiser, Grünenthal, Hexal, Indivior, Kaia Health, Lilly, Medscape Mundipharma, MSD, Novartis, Pfizer, Recordati Pharma, Sanofi-Aventis, and TAD Pharma, Speakers bureau: AOP Orphan, Almiral Hermal, Bionest Partners, Benkitt Renkiser, Grünenthal, Hexal, Indivior, Kaia Health, Lilly, Medscape Mundipharma, MSD, Novartis, Pfizer, Recordati Pharma, Sanofi-Aventis, and TAD Pharma, Michael Hammer Consultant of: Abbvie, Pfizer, Medac and Janssen, Speakers bureau: Abbvie, Pfizer, Medac and Janssen, Christoph Baerwald Consultant of: CGB received speaker or consulting fees from AbbVie, Paid instructor for: CGB received speaker or consulting fees from AbbVie, Speakers bureau: CGB received speaker or consulting fees from AbbVie, Jochen Walter Consultant of: Pfizer, Speakers bureau: AbbVie, Frauenhofer Institut, Gilead, Janssen-Cilag, Medac, Novartis, Pfizer, Ralf Schröder Shareholder of: Pfizer Pharma $\mathrm{GmbH}$, Employee of: Pfizer Pharma $\mathrm{GmbH}$, Matthias Schneider Grant/research support from: GSK, UCB, Abbvie, Consultant of: Abbvie, Alexion, Astra Zeneca, BMS, Boehringer Ingelheim, Gilead, Lilly, Sanofi, UCB, Speakers bureau: Abbvie, Astra Zeneca, BMS, Chugai, GSK, Lilly, Pfizer, Sanofi, Ralf Baron Consultant of: RB received speaker or consulting fees from AbbVie, Paid instructor for: RB received speaker or consulting fees from AbbVie, Speakers bureau: RB received speaker or consulting fees from AbbVie

DOI: 10.1136/annrheumdis-2020-eular.4457

\section{THU0479 ASSOCIATION BETWEEN CENTRAL SENSITIZATION AND CLINICAL AND ULTRASONOGRAPHIC PARAMETERS IN INFLAMMATORY ARTHRITIDES}

G. Adami ${ }^{1}$, E. Gerratana ${ }^{2}$, A. Giollo ${ }^{1}$, C. Benini ${ }^{1}$, E. Vantaggiato ${ }^{1}$, D. Rotta ${ }^{1}$, L. Idolazzi ${ }^{1}$, D. Gatti ${ }^{1}$, M. Rossini ${ }^{1}$, A. Fassio ${ }^{1} .{ }^{1}$ University of Verona, Verona, Italy; ${ }^{2}$ University of Messina, Messina, Italy

Background: Central sensitization (CS) is an important feature of patients with chronic pain, especially rheumatoid arthritis (RA) and psoriatic arthritis (PsA) patients. CS might interfere with the clinical evaluation of inflammation. Central Sensitization Inventory (CSI) is a validated instrument for assessing central sensitization.

Objectives: We seek to investigate the inference of central sensitization (assessed with the CSI) on clinical (disease activity scores) and ultrasound parameters (US 7-joints score) in RA and PSA patients.

Methods: We conducted a cross-sectional analysis on patients with an established diagnosis of RA or polyarticular PsA. Demographic, anamnestic and clinical parameters were collected. Disease activity was measured with SDAI in RA patients and with DAPSA in PsA patients. The presence and severity of synovitis was measured with the US 7-joints score. Exclusion criteria included: diagnosis of fibromyalgia, depression and patients with PsA with enthesitis predominant and/or spondylitis subtypes. Differences between variables were analysed with t-test and ANOVA for multiple comparisons. Correlation between continuous variables was analysed with Pearson correlation. CSI was analysed either as positivelnegative (threshold 40 points) or divided in four categories, i.e., subclinical ( $\leq 29)$, mild (30-39), moderate (40-49), severe (50$59)$ and extreme $(\geq 60)$.

Results: We enrolled 42 patients in the study. Descriptive characteristics of the study population are presented in table 1. We found no difference in clinical parameters between diseases, sex or age. Women had a higher CSI score compared to men (mean 39.3 vs $26.7 p=0.005$ ). We found a correlation between CSI score and DAPSA $\left(r^{2} 0.39, p=0.001\right)$, number of tender joints $\left(r^{2} 0.13, p=0.02\right)$ and $\mathrm{HAQ}\left(r^{2} 0.47, \mathrm{p}<0.001\right)$ (Figure 1) while we found no correlation between CSI score and SDAI or other clinical parameters. We found a significant difference in DAPSA, tender joints count and HAQ between CSI categories (ANOVA $p=0.01$, $p=0.02$ and $p<0.001$ respectively). US 7-joints score was associated with SDAI $\left(r^{2}\right.$ $0.33, p=0.03)$, number of swollen joints $\left(r^{2} 0.28, p=0.002\right)$ and disease duration $\left(r^{2} 0.35, p<0.001\right)$ but not with DAPSA or tender joints.
Table 1. Descriptive characteristics of the study population

\begin{tabular}{llc}
\hline Age (mean, SD in years) & & $55.9(12.3)$ \\
\hline BMI & & $25.9(3.9)$ \\
CSI questionnaire score (mean) & & $35(16)$ \\
CSI categories (n, \%) & Subclinical & $18(42.9 \%)$ \\
& Mild & $9(21.4 \%)$ \\
& Moderate & $8(19.0 \%)$ \\
& Severe & $4(9.5 \%)$ \\
Diagnosis (n, \%) & Extreme & $3(7.1 \%)$ \\
& PsA 52.4\% & 9 men 13 women \\
CSI score in PsA (mean, SD) & RA 47.6\% & 2 men 18 women \\
CSI score in RA (mean, SD) & & $34.4(16.5)$ \\
CRP (median, IQR in mg/L) & & $34.8(15.5)$ \\
Tender joints (mean, SD) & & $1.85(1.0-4.6)$ \\
Swollen joints (mean, SD) & & $2(2)$ \\
SDAI categories (n, \%) & Remission & $1(2)$ \\
& Low disease activity & $4(20.0 \%)$ \\
& Moderate disease activity & $8(40.0 \%)$ \\
DAPSA categories (n, \%) & Severe disease activity & $7(35.0 \%)$ \\
& Remission & $1(5.0 \%)$ \\
& Low disease activity & $6(33.3 \%)$ \\
& Moderate disease activity & $4(22.2 \%)$ \\
US 7-joints score (mean, SD) & Severe disease activity & $7(38.9 \%)$ \\
HAQ (mean, SD) & & $1(5.6 \%)$ \\
Prednisone equivalent (mean, SD in mg/day) & $6(7)$ \\
Biological DMARD (n, \%) & No & $0.6(0.6)$ \\
Conventional DMARD (n, \%) & Yes & $1.47(3.2)$ \\
& No & $15(35.7 \%)$ \\
& Yes & $27(64.3 \%)$ \\
& & $13(31.0 \%)$ \\
& & $29(69.0 \%)$ \\
\hline
\end{tabular}

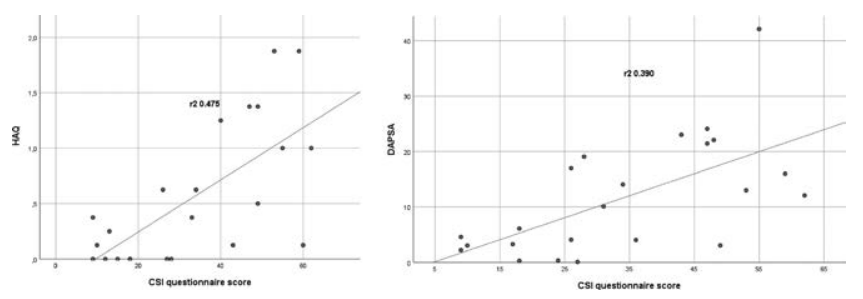

Figure 1. Correlation between DAPSA score and CSI score and between HAQ and CSI score

Conclusion: We found an association between CS and sex, functional disability, tender joints count and disease activity score in PsA patients while there was no correlation between RA disease activity and central sensitization. US 7-joints score was associated with swollen joints count, disease duration and disease activity in RA patients but not in PsA patients. In PsA patients, DAPSA might be more influenced by central sensitization, especially in female individuals.

Disclosure of Interests: Giovanni Adami: None declared, Elisabetta Gerratana: None declared, Alessandro Giollo: None declared, Camilla Benini: None declared, Elisabetta Vantaggiato: None declared, Denise Rotta: None declared Luca Idolazzi: None declared, Davide Gatti Speakers bureau: Davide Gatti reports personal fees from Abiogen, Amgen, Janssen-Cilag, Mundipharma, outside the submitted work., Maurizio Rossini Speakers bureau: AbbVie, Abiogen, Amgen, BMS, Eli-Lilly, Novartis, Pfizer, Sanofi, Sandoz and UCB, Angelo Fassio Speakers bureau: Angelo Fassio reports personal fees from: Abiogen and Novartis, outside the submitted work.

DOI: 10.1136/annrheumdis-2020-eular.3676

\begin{tabular}{l|l}
\hline THU0480 & EXPERIENCE USING DIFFERENT CRITERIA OF \\
& FIBROMYALIA IN PATIENTS WITH ANKYLOSING \\
& SPONDYLITIS: 1990 AMERICAN COLLEGE OF \\
& RHEUMATOLOGY CLASSIFICATION CRITERIA VS. \\
& NEW
\end{tabular}

I. Shapoval ${ }^{1}$, M. Stanislavchuk ${ }^{1}, \mathrm{H}$. Movchan ${ }^{1} .{ }^{1}$ National Pirogov Memorial Medical University, Vinnytsya, Ukraine, Chair of Internal Medicine $\#^{1}$, Vinnytsya, Ukraine

Background: Fibromyalgia (FM) is a very frequent condition in patients with diseases associated with pain syndrome, such as rheumatoid arthritis (RA), ankylosing spondylitis (AS) and other chronic rheumatic diseases. FM, RA and AS has different clinical characteristics, but can share symptoms such as pain, fatigue and sleep disturbance that leads to delay in appropriation correct diagnosis [1] For today well known many different criteria for FM: 1990 American College of Rheumatology (ACR) classification criteria, modified 2010 ACR diagnostic criteria, 2016 Fibromyalgia Diagnostic Criteria and new AAPT Diagnostic Criteria for 